\title{
Processo de trabalho e os resultados dos Núcleos de Apoio à Saúde da Família de um município do Sul do Brasil: o olhar do enfermeiro
}

\author{
Francielle Rosso Mazzuchello*, Luciane Bisognin Ceretta, M.Sc.**, Valdemira Santina Dagostin, M.Sc. ${ }^{* * *}$,
} Francielle Lazzarin de Freitas Gava****

*Universidade do Extremo Sul Catarinense (UNESC), **Professora do curso de enfermagem e Coordenadora da Unidade de Ciências da Saúde da Universidade do Extremo Sul Catarinense (UNESC, ***Professora do curso de enfermagem da Universidade do Extremo Sul Catarinense (UNESC), ${ }^{* * *}$ Especialista em Saúde Coletiva com área de concentração em Saúde da Família e em Gerenciamento de Unidades Básicas de Saúde. Professora do curso de enfermagem da Universidade do Extremo Sul Catarinense (UNESC)

\section{Resumo}

A presente pesquisa teve como objetivo identificar os resultados do projeto Núcleo de Apoio à Saúde da Família (NASF) oferecido às unidades de referência em um município do sul do Brasil, a partir da organização do processo de trabalho na ótica dos enfermeiros. Trata-se de um estudo de abordagem qualitativa, descritiva cuja coleta de dados foi feita por meio de uma entrevista semiestruturada com os enfermeiros que atuam nas unidades de saúde da família apoiadas pelos NASF. Os sujeitos do estudo constituíram-se de 24 enfermeiros. Os resultados da pesquisa denotam as dificuldades encontradas na organização do processo de trabalho do NASF, observando-se que essa organizaçâo encontra-se ainda fragmentada, isolada das equipes, sem discussóes de casos e elaboração de projetos terapêuticos, constatando-se que as diretrizes nacionais do NASF não são seguidas pelos seus integrantes na sua totalidade, o que demonstra um apoio matricial oferecido às Unidades de Saúde da Família ainda falho. Concluiu-se que a proposta de implantação do NASF no município necessita de profissionais instrumentalizados, estruturados e com perfil para atuação no cenário da saúde da família para que essa proposta possa ser efetivada.

Palavras-chave: atenção primária à saúde, saúde da família, Enfermagem, promoção da saúde.

\section{Abstract \\ Work process and results of support in Family Health Units of a city in Southern Brazil: a nurse point of view}

This study aimed to identify the results of support in Family Health Units project provided to reference units of a city in southern Brazil, related to organization of work process from a nurse point of view. This was a qualitative and descriptive study. Data was collected using a semi-structured interview with nurses who worked in family health units supported by NASF. The study subjects consisted of 24 nurses. The survey results showed difficulties found in the organization of work process of the 
NASF, and observed that the organization is still fragmented, isolated from teams, without case discussions and elaboration of therapeutic projects. Also, national guidelines of NASF are not followed by the members as a whole, which shows a matrix support offered to the Family Health Units defective. We conclude that the implementation of NASF in the city needs trained and well-structured professionals with profile to work in the health family scenario in order to accomplish this objective.

Key-words: primary health care, family health, Nursing, health promotion.

\section{Resumen}

\section{Proceso de trabajo y los resultados del Núcleo de Apoyo a la Salud de la Familia de un municipio en el sur de Brasil: desde la óptica del enfermero}

Esta investigación tuvo como objetivo identificar los resultados del proyecto Núcleo de Apoyo a la Salud de la Familia (NASF) ofrecido a las unidades de referencia en un municipio en el sur de Brasil, a partir de la organización del proceso de trabajo desde la óptica del enfermero. Se trata de un estudio cualitativo, descriptivo y la recolección de datos se realizó a través de una entrevista semiestructurada con enfermeros que trabajan en unidades de salud familiar apoyados por el NASF. Los sujetos de estudio fueron 24 enfermeros. Los resultados de la investigación indican las dificultades encontradas en la organización del proceso de trabajo del NASF, señalando que la organización aún se encuentra fragmentada, equipos aislados, sin discusiones de casos y elaboración de proyectos terapéuticos, y se constató que las directrices nacionales NASF no son seguidas por sus miembros como un todo, lo que demuestra un soporte matricial ofrecido a las Unidades de Salud de la Familia aún defectuoso. Se concluyó que la propuesta de implementación del NASF en el municipio necesita de profesionales instrumentalizados, estructurados y con perfil para trabajar en el escenario de la salud de la familia para que esta propuesta pueda ser efectiva.

Palabras-clave: atención primaria de la salud, salud de la familia, Enfermería, promoción de la salud.

\section{Introdução}

O Núcleo de Apoio à Saúde da Família (NASF) foi constituído pelo Ministério da Saúde por meio da portaria GM no 154 , de 24 de janeiro de 2008, com o objetivo de apoiar à inserção da Estratégia de Saúde da Família na rede de serviços e ampliar a abrangência, a resolutividade, a territorialização, a regionalização, bem como a ampliação das açóes da atenção básica no Brasil [1].

Tais núcleos devem ser constituídos por uma equipe, na qual profissionais de diferentes áreas de conhecimento atuam em conjunto com os profissionais da equipe de Saúde Família compartilhando e apoiando as práticas em saúde nos territórios sob responsabilidade destas equipes [1].

O NASF é um projeto recente, cuja essência reúne potencial para contribuir de modo significativo com a consolidação da Estratégia Saúde da Família (ESF) e do próprio Sistema Único de Saúde (SUS), motivo pelo qual é importante compreender como os enfermeiros que atuam na gerência das Unidades de Saúde da Família adstritas ao NASF compreendem e vivenciam essa proposta. Entende-se que a percepção do enfermeiro que atua como gerente das Unidades de Saúde da Família apoiadas pelo NASF seja essencial, enquanto norteadora para as intervenções dos núcleos.

Cabe enfatizar que este núcleo trabalha de forma integrada com as redes de serviço, a partir das necessidades encontradas junto com a equipe das Estratégias de Saúde da Família, portanto não é porta de entrada para o sistema, mas sim, um apoio para a equipe de saúde na atenção básica enfatizando a promoção a saúde e não a assistência especializada [1].

Concorda-se quando os autores refletem que a interdisciplinaridade possibilita reconstruir uma prática de açóes voltadas aos diversos saberes profissionais e, deste modo, criar uma intervenção comum à equipe baseada na realidade das demandas daquele território [2].

Nesse contexto, verificam-se ainda algumas dificuldades enfrentadas pela equipe do NASF para o desenvolvimento de suas atividades em grupo, pois esses profissionais inclusos nos NASF são voltados para a formação assistencialista/especializada em sua maioria, tendo entáo que se adaptar a esse novo meio que procura não o atendimento individual exceto em certas condiçóes específicas - mas sim, o compartilhamento em grupos [3].

Diante dessa contextualização e das discussóes sobre o assunto, elaborou-se para a pesquisa 
o seguinte questionamento: Qual a contribuiçáo do NASF, em um município do sul do Brasil, a partir de o apoio matricial oferecido às Unidades de Referência em Saúde da Família? O objetivo do presente estudo foi de identificar os resultados do NASF oferecido às unidades de referência em um município do sul do Brasil, a partir da organização do processo de trabalho na ótica dos enfermeiros.

\section{Material e métodos}

Trata-se de um estudo de cunho qualitativo e descritivo. Participaram do estudo 24 enfermeiros que atuam nas unidades de saúde da família de um município do Sul do Brasil.

A coleta de dados foi realizada no período de julho a agosto de 2011, por meio de entrevistas semiestruturadas com os enfermeiros e após assinatura do Termo de Consentimento Livre e Esclarecido (TCLE). Após a coleta de dados, as informaçóes foram agrupadas, categorizadas por temas e discutidas com base na compreensão sobre esses resultados, utilizando-se a análise de conteúdo de Bardin [4].

Durante o desenvolvimento do estudo, foi garantido o anonimato dos entrevistados, conforme determina a Resoluçáo nº 196/96. A digitação das respostas dos entrevistados foi fiel ao mencionado, identificando os sujeitos como E1, E2, E3, respectivamente. $\mathrm{O}$ estudo obteve aprovação do Comitê de Ética em Pesquisa da Universidade do Extremo Sul Catarinense - UNESC, com o registro de número 190/2011.

\section{Resultados e discussão}

Para compreender como se processa a articulaçáo do trabalho desenvolvido pelos NASF às unidades de saúde da família na ótica dos enfermeiros foram analisados seis unidades temáticas: Atividades desenvolvidas pelo NASF; Planejamento conjunto das atividades do NASF com a equipe de Saúde da Família; Retorno dos atendimentos efetuados pelo NASF à equipe de referência; Seguimento das diretrizes nacionais pelas equipes do NASF; Preparo dos profissionais para atuarem no NASF e Avaliação sobre os resultados do NASF para a Saúde da Família.

\section{Atividades desenvolvidas pelo NASF}

As atividades desenvolvidas pelo NASF na opiniáo dos enfermeiros entrevistados referem-se, principalmente, às atividades de apoio a grupos terapêuticos e com muita frequência surge a caminhada orientada. Não são relatadas atividades coerentes com as diretrizes do NASF tais como: visitas domiciliares, construção de projetos terapêuticos singulares e de território dentre outras. As atividades são individuais dos integrantes do NASF e não apresentam, ao olhar dos enfermeiros, forte interlocução com as equipes, tal qual propóem as diretrizes. A fala a seguir remete a análise explícita.

\footnotetext{
"Desde quando atuam fizeram dois grupos só, não fazem mais; fazem raros atendimentos individuais; [...] eles não fazem seu papel. Não priorizam nenhuma coisa e nem outra”. (E8)
}

Entende-se que esta fragmentação das atividades desenvolvidas pelo NASF fragiliza a proposta de apoio matricial.

No documento que trata das diretrizes do NASF este organizará o seu processo de trabalho com foco nos territórios de sua responsabilidade, conjuntamente com as equipes de SF que a ele se vinculam de forma a priorizar: açóes clínicas compartilhadas, para uma intervenção interdisciplinar, com troca de saberes, capacitação e com ênfase em estudo e discussão de casos, realização de projeto terapêutico singular, espaços de reunióes, bem como consultas/atendimentos conjuntos, etc. Intervençóes específicas do profissional do NASF com os usuários e/ou famílias, com discussão e negociação a priori com os profissionais da equipe de SF responsáveis pelo caso, de forma que o atendimento individualizado pelo NASF se dê apenas em situaçóes extremamente necessárias [5].

Ações compartilhadas nos territórios de sua responsabilidade devem ser desenvolvidas de forma articulada com as equipes de SF, bem como o desenvolvimento de um projeto de saúde no território, planejamentos, reunióes, apoio aos grupos, trabalhos educativos, de inclusão social, enfrentamento da violência, açóes junto aos equipamentos públicos, como escolas, creches, igrejas, pastorais etc. [6].

$\mathrm{O}$ apoio matricial em saúde objetiva assegurar retaguarda especializada as equipes e profissionais encarregados da atenção a problemas de saúde. Trata-se de uma metodologia de trabalho complementar àquela prevista em sistemas hierarquizados, a saber: mecanismos de referência e contrarreferência, protocolos e centros de regulação [7]. 
A falta de organização das atividades, sobretudo com um cunho muito individualista, além de corromper a proposta do matriciamento e da clínica ampliada, leva ao descrédito a representação desta proposta no imaginário dos enfermeiros e consequentemente da equipe multiprofissional de saúde.

\section{Planejamento conjunto das atividades do NASF com a equipe de Saúde da Família}

Constata-se que o planejamento das atividades junto aos enfermeiros acontece de modo muito incipiente, sem organização e sistematização. Esta atitude compromete a credibilidade do programa junto aos enfermeiros e também junto à população.

"Não. Acontece mais individual e quando há necessidade". (E4)

"Poucas vezes discutimos as ideias em conjunto”. (E7)

$\mathrm{Na}$ ótica dos enfermeiros entrevistados não há um planejamento conjunto de atividades, de acordo com as demandas da comunidade. Mesmo os enfermeiros que responderam positivamente a esta questão referem que não há um planejamento de fato, que seja efetivo.

O processo de implementação do NASF implica a necessidade de estabelecer espaços rotineiros de discussóes e de planejamento em equipe (NASF) e entre equipes (NASF e equipe de SF). Com reunióes para definir objetivos, critérios de prioridades, critério de avaliação dos trabalhos, resolução de conflitos, discussões de casos/situaçóes, entre outros [5].

O trabalho em equipe entra como uma proposta estratégica, como forma de subsídio aos profissionais para melhor lidar com o processo de especializaçóes na saúde, de forma que vise a um aspecto individualizado produzindo conhecimentos e intervençóes verticalizadas. Assim, o trabalho em equipe pretende contemplar a articulação das açóes e dos saberes simultaneamente [8].

Atrelado a isso, o Apoio Matricial facilita a vinculação do usuário nos serviços da rede, sem que haja a diluição de responsabilidades, pois os casos acabam sendo compartilhados no momento da reuniáo, a fim de que se saiba como está sendo $o$ andamento dos mesmos.

\section{Retorno dos atendimentos efetuados pelo NASF à equipe de referência}

Nas falas descritas a seguir, verifica-se a falta de retorno dos casos acompanhados para a equipe de referência, demonstrando uma atuação falha no sentido de apoio do NASF a essas equipes. Essa falta de retorno dificulta a implantação da proposta do NASF, uma vez que este vem apoiar as ESF e, portanto, náo é a porta de entrada do serviço. Para tanto, faz-se necessário repensar o processo de trabalho que deve ser pensado na lógica de uma equipe interdisciplinar em que as açóes planejadas ocorram em conjunto, permeando vários saberes e construindo várias estratégias para o bem da comunidade.

"Não retornam". (E2)

"Nem todos, alguns sim". (E4)

A falta de retorno dos atendimentos desenvolvidos pelos integrantes do NASF para a equipe de referência é um ponto de significativa importância a ser discutido, tendo em vista que se não houver um retorno dos atendimentos e dos planos terapêuticos desenvolvidos há fragmentação no processo de cuidar dos sujeitos, e esta não é a proposta do NASF.

Trabalhar para a construção de uma prática interdisciplinar remete uma aproximação entre as partes envolvidas, no qual o diálogo é a ferramenta essencial para uma aproximação entre as equipes, e todo conhecimento parcial só ganha importância e significado quando compartilhado e trabalhado no conjunto [9].

Atuar como apoio matricial implica em decidir conjuntamente as açóes, construir coletivamente os projetos terapêuticos e, sobretudo, oferecer retorno dos casos atendidos.

\section{Seguimento das diretrizes nacionais pelas equipes do NASF}

Referente ao seguimento das diretrizes nacionais pelas equipes do NASF, verifica-se que esse processo apresenta-se falho diante do cenário apresentado, a fala a seguir demonstra a análise explícita.

"Algumas sim, outras não. Alguns, por exemplo, seguem quando se empenham em fazer ou auxiliar em algum grupo, porém outros profissionais não fazem nem grupos e nem atendimentos individuais”. (E2) 
Constata-se uma carência significativa de comprometimento dos integrantes do NASF para com as atividades que necessitam de apoio matricial pelas equipes de referência. Percebe-se nitidamente na fala deste enfermeiro que nem todos os integrantes do NASF são empenhados e colaborativos.

"Eu acho que aqui a equipe do NASF está bem ausente, só aparece de 15 em 15 dias nesse grupo de obesidade".

A ausência da equipe do NASF à unidade de saúde, comparecendo a cada 15 dias, compromete o processo de trabalho e está completamente contrário ao que preconizam as diretrizes do NASF.

Trabalhar em saúde da família quer seja em equipes de referência, quer seja em equipes apoiadoras matriciais, como é o caso do NASF, implica em reorganizar os horários com a finalidade de atender as demandas da população, das comunidades e das próprias unidades de saúde. A náo participação dos integrantes do NASF aos convites para reunióes da equipe de referência após o horário de trabalho, sendo que este pode ser compensado, torna-se um significativo fator limitante para que o processo de trabalho seja adequadamente organizado e para que o NASF participe da vida das comunidades.

"Eu nem sei se eles sabem o que é isso".

$\mathrm{Na}$ visão dos enfermeiros entrevistados os integrantes do NASF desconhecem as diretrizes da proposta e por esse motivo náo as aplicam. Nesse âmbito o NASF constitui-se como um passo importante para a consolidação da ESF e para o aprimoramento deste novo modelo de traballho inserindo uma equipe ampla, multiprofissional e interdisciplinar na APS. Com foco nesse modelo, as diretrizes como integralidade, equidade e participação social devem ser concretizadas em açóes conjuntas e com ênfase no desenvolvimento humano e na promoçáo a saúde, ultrapassando o marco assistencialista e individualista [10].

\section{Preparo dos profissionais para atuarem no NASF}

O preparo dos profissionais para atuarem no NASF na visão de alguns enfermeiros apresenta-se razoavelmente bom, porém apontam alguns aspectos a serem melhorados em relação a um planejamento mais efetivo, um direcionamento eficaz das açóes propostas, objetivos e metas definidas. As falas a seguir demonstram este cenário.

\footnotetext{
"Sim, só tem que melhorar em alguns itens como um planejamento mais efetivo". (E1) "Sim. Mas falta união entre eles, por exemplo, um dia pedi que um profissional falasse sobre medicaçáo no grupo da psicóloga, ai ela falou que náo, porque o grupo não era dela. Mas eu acho que o trabalho é de todos". (E2)
}

O NASF deve atuar dentro de algumas diretrizes relativas à APS, a saber: ação interdisciplinar e intersetorial; educação permanente em saúde dos profissionais e da populaçáo; desenvolvimento da noção de território; integralidade, participação social, educação popular; promoçáo da saúde e humanização.

Assim, a organização dos processos de trabalho do NASF, com foco no território sob sua responsabilidade, deve ser estruturada priorizando o atendimento compartilhado e interdisciplinar, com troca de saberes, capacitaçáo e cadernos de responsabilidades mútuas, gerando experiência para todos os profissionais envolvidos, mediante amplas metodologias, tais como estudo e discussão de casos e situaçóes, projetos terapêuticos, orientaçóes e atendimento conjunto etc. Intervençóes diretas do NASF frente a usuários e famílias podem ser realizadas, mas sempre sob encaminhamento das equipes de saúde da família com discussóes e negociação a priori entre os profissionais responsáveis pelo caso.

Nas falas avaliadas negativamente pelos enfermeiros, constata-se que falta entrosamento, interação com a equipe de referência, trabalho em equipe, multidisciplinaridade e interdisciplinaridade.

"Ainda não, falta ainda entrosamento com a equipe de SF”. (E3)

A falta de entrosamento apontada pelos enfermeiros implica dizer que o trabalho em equipe entre NASF e equipe de referência encontra-se defasado no município do estudo. $\mathrm{O}$ trabalho em equipe mesmo considerado importante é um processo difícil. Nele os sujeitos envolvidos procuram dividir responsabilidades, a fim de chegar o mais rapidamente possível na resolução de um caso ou situação-problema. 
Nos serviços de atenção básica as equipes de profissionais enfrentam dificuldades em organizar seu trabalho. Compor-se e manejar-se, enquanto equipe, estabelecer equilíbrio entre atividades de acolhimento e atividades planejadas, discutir casos e implementar projetos terapêuticos que ampliem a clínica com centralidade no sujeito (usuário) são atividades que têm sido deixadas de lado em função do cumprimento de tarefas, de uma forma mecânica, como "dar conta" da "demanda espontânea" que procura as Unidades Básicas de Saúde e do atendimento ambulatorial tradicional por "programas", condenando os serviços ao funcionamento burocratizado e médico-centrado [11].

\section{Avaliaçáo sobre os resultados do NASF para a Saúde da Família}

Como se observa nas falas abaixo, os enfermeiros avaliam os resultados do NASF para a ESF positivamente, porém expóem pontos pertinentes de que esta avaliação apresenta-se omissa, tendo em vista que a falta de empenho, um trabalho individualizado e não efetivo remete a ideia de que o resultados do NASF para ESF não está sendo totalmente satisfatório e condizente com a proposta do mesmo.

\footnotetext{
"Um bom trabalho, as pessoas que participam dos grupos deles gostam. Falta um pouco mais de empenho. Sugere-se trabalho em equipe, pois estão trabalhando individualmente, tem que ter trabalho de equipe entre eles. Tem auxiliado, porém resolvido os problemas mesmo, não". (E2)
}

Por se tratar de um processo em construçáo, a implantação do NASF implica a necessidade de estabelecer espaços rotineiros de reunióes, planejamentos e discussóes de casos para definição de projetos terapêuticos compartilhados por toda a equipe, de forma validada e significativamente reconhecida sob o ponto de vista dos gestores, na forma de projetos terapêuticos singulares (PTS) e projetos de saúde no território (PST) [12].

Dentre as dificuldades que estão sendo identificadas no processo de trabalho do NASF está a formação dos profissionais que não atendem às necessidades do SUS, muito menos da atenção básica. O distanciamento dos serviços na formulação das propostas pedagógicas para formaçáo inicial, assim como a iniciativa crescente de educaçáo à distância na pós-graduação, não contempla questóes tão singulares como vínculo, acolhimento, escuta e o próprio trabalho em equipe, indispensáveis para a proposta do NASF [12].

\begin{abstract}
"Eu não conheço muito o trabalho do NASF. Poderia ser melhor tanto com a equipe de SF (discussão de casos) e pacientes (pois atendimentos individuais todos fazem, não precisa do NASF para isso) precisa de inovação. Sugere-se inovar $[. .$.$] precisa de criatividade$ [...] A equipe esta muito dividida NASF e NASF e equipe de SF. [...]" (E7)
\end{abstract}

Trabalhar em conjunto com a equipe de referência é a estratégia fundamental para que a proposta do NASF se consolide. A ESF é uma grande aliada para a qualificação do processo de trabalho do NASF, deste modo, não há processo de trabalho que se encontre eficaz para a ESF sem que ambas as equipes tenham forte interlocução.

A proposta do NASF tem na clínica ampliada o conceito norteador das açóes, não para reduzir os usuários a um recorte diagnóstico ou por áreas profissionais, mas como uma ferramenta para que os profissionais e gestores dos serviços de saúde possam enxergar e atuar na clínica para além dos pedaços fragmentados, sem deixar de reconhecer e utilizar o potencial desses saberes [11].

Por se tratar de uma estratégia recente no campo da saúde, percebemos que o cotidiano desta prática encontra-se em processo de construção na rede. Ainda enfrentando algumas dificuldades até mesmo com relação ao seu papel. Há um equívoco frequente que é o de considerar o apoio matricial como supervisão de caso, o que náo vai ao encontro com a proposta inicial do apoio que é o do envolvimento, de produzir desvio na forma como são feitos os procedimentos com o usuário.

Deste modo, acreditamos ser necessário que a experiência do apoio matricial pelo NASF seja posta em análise entre seus atores, no intuito de favorecer sua potencialidade de agenciar mudanças nas práticas hegemônicas da saúde, a fim de não incorrer no erro de se tornar um modo cristalizado de trabalho.

\section{Conclusão}

Concluiu-se no estudo que a efetividade do NASF enquanto apoio para as estratégias de saúde da família no município do estudo não se encontra, 
de fato, adequada. Constatou-se pouca resolubilidade das açóes efetuadas pelos núcleos de apoio a saúde da família nas unidades de referência. Os resultados da pesquisa denotam dificuldades encontradas na organização do processo de trabalho do NASF, constatando-se que essa organização encontra-se isolada das equipes, sem discussóes de casos e elaboração de projetos terapêuticos, constatando-se que as diretrizes nacionais do NASF não são seguidas totalmente pelos seus integrantes, o que demonstra um apoio matricial oferecido às Estratégias de Saúde da Família insatisfatório. Constatou-se ainda o despreparo dos profissionais do NASF para atuação na Saúde da Família, demonstrando um olhar voltado para a área clínica.

Os enfermeiros apresentam uma avaliação negativa em relação ao processo de trabalho do NASF para as açóes prestadas às unidades de referência. Percebeu-se que alguns pontos prioritários foram ressaltados pelos enfermeiros que refletem num processo de trabalho inadequado, como a falta de um planejamento efetivo, de uma agenda fixa, de um cronograma junto às ESF e ainda a falta de conhecimento da realidade do território, implicando em açôes e intervençôes não condizentes com as demandas populacionais. Essa avaliação dos enfermeiros faz refletir sobre a forma como os núcleos desenvolvem o processo de trabalho das unidades de saúde da família e a pouca contribuição do NASF, enquanto apoio para essas unidades.

Entende-se assim que os Núcleos surgem como apoio a essas unidades de saúde da família, de forma a proporcionar as mesmas uma melhor maneira de reorganizar o modelo de saúde contribuindo para a ampliação do vínculo com a população e da continuidade do cuidado. Diante de tais fatos, percebe-se que para a proposta da implantaçáo do NASF nos municípios serem de fato efetivas é necessário que os núcleos sejam e estejam bem instrumentalizados, estruturados e detenham de profissionais com perfil adequado para atuaçáo no complexo cenário da saúde da família.

\section{Referências}

1. Ministério da Saúde. Ações e Programas. Portaria $\mathrm{n}^{\circ} 154 / \mathrm{GM}$, de 24 de janeiro de 2008, republicada em 04 de março de 2008. Cria o NASF. Brasília: MS; 2011

2. Araújo MBS, Rocha PM. Trabalho em equipe: um desafio para a consolidação da estratégia de saúde da família. Ciênc Saúde Coletiva 2007;12(2):455-64.

3. Barbosa EG, Ferreira DLS, Furbino SAR. Experiência da fisioterapia no Núcleo de Apoio à Saúde da Família em Governador Valadares, MG. Fisioter Mov 2010;23(2):323-30.

4. Bardin L. Análise de conteúdo. Traduzido por: Reto LA, Pinheiro A. Lisboa: Ediçóes 70; 2002.

5. Ministério da Saúde. Secretaria de Atenção à Saúde. Departamento de Atenção Básica. Diretrizes do NASF: Núcleo de Apoio a Saúde da Família. (Série A. Normas e Manuais Técnicos) (Caderno de Atenção Básica, n. 27). Brasília: MS; 2010. 152 p.

6. Ministério da Saúde. Secretaria de Atenção à Saúde. Departamento de Atenção Básica. Cadernos de Atenção Básica. Diretrizes do NASF. (Série A. Normas e Manuais Técnicos) (Cadernos de Atenção Básica ; n. 27). Brasília: MS; 2009. 160 p.

7. Campos GWS, Domitti AC. Apoio matricial e equipe de referência: uma metodologia para gestáo do trabalho interdisciplinar em saúde. Cad Saúde Pública 2007;23(2): 399-407.

8. Pavoni DS, Medeiros CRG. Processos de trabalho na equipe Estratégia de Saúde da Família. Rev Bras Enferm 2009;62(2): 265-71.

9. Kell MCG, Shimizu HE. Existe trabalho em equipe no Programa Saúde da Família? Ciênc Saúde Coletiva 2010;15(1):1533-41.

10. Molini-Avejonas DR, Mendes VLF, Amato CAH. Fonoaudiologia e Núcleos de Apoio à Saúde da Família: conceitos e referências. Rev Soc Bras Fonoaudiol 2010;15(3):465-74.

11. Oliveira RG, Marcon SS. Trabalhar com famílias no Programa de Saúde da Família: a prática do enfermeiro em Maringá-Paraná. Rev Esc Enferm USP 2007;41(1): 65-72.

12. Nascimento DDG, Oliveira MAC. Reflexóes sobre as competências profissionais para o processo de trabalho nos Núcleos de Apoio à Saúde da Família. O Mundo da Saúde 2010;34(1):92-96. 